\title{
Associação Brasileira de Enfermagem no contexto da reforma educacional de 1996
}

\author{
Associação Brasileira de Enfermagem in the context of the educational reform of I 996 \\ Associação Brasileira de Enfermagem en el contexto de la reforma educacional del 1996
}

\author{
Maria Lelita Xavier', Suely de Souza Baptista' \\ 'Universidade Federal do Rio de Janeiro. Escola de Enfermagem Anna Nery. \\ Núcleo de Pesquisa de História da Enfermagem Brasileira. Rio de Janeiro, RJ
}

Submissão: 12/12/2008

Aprovação: 05/01/2010

\section{RESUMO}

Estudo histórico-social tendo como objeto: estratégias de luta de porta-vozes da enfermagem frente às diretrizes emanadas da Lei de Diretrizes e Bases da Educação Nacional/1 996. Objetivos: analisar a posição da ABEn no campo da educação superior de enfermagem; discutir estratégias de luta empreendidas por porta-vozes da educação superior de enfermagem frente às diretrizes da LDB/96. Fontes primárias: depoimentos orais e documentos escritos. Fontes secundárias: literaturas sobre a temática. Referencial teórico: conceitos de Pierre Bourdieu. As estratégias de luta empreendidas pelos agentes da enfermagem aconteceram a partir de diretrizes político-expansionistas, político-jurídicas, e político-organizacionais, as Quais concorreram para a reconfiguração do campo da educação superior de enfermagem. Descritores: Enfermagem; História da enfermagem; Educação em enfermagem.

\section{ABSTRACT}

Socio-historical study having as object nursing spokesmen's fight strategies in front of policies come from the Policies and Bases Law of the National Education /1996. Objectives: to analyze the ABEn's position in field of the nursing superior education; discuss the fight strategies undertaken by spokesmen of the nursing superior education in front of the LDB/96's policies. Primary sources: oral depositions and written documents. Secondary sources: literatures about the thematic. Theoretical Reference: Pierre Bourdieu's concepts. The fight strategies undertaken by the nursing agents occurred from the political-expansionist, political-juridical and politic - organizational policies, which concurred to the reconfiguration of the nursing superior education field's reconfiguration.

Key words: Nursing; Nursing history; Education, nursing.

\section{RESUMEN}

Estudio histórico-social teniendo como objeto: estrategias de lucha de porta-voces de la enfermería frente a las directrices emanadas de la Ley de Directrices y Bases de la Educación Nacional/1996. Objetivos: analizar la posición del ABEn en el campo de la educación superior de enfermería; discutir estrategias de lucha emprendidas por porta-voces de la educación superior de enfermería frente a las directrices de la LDB/96. Fuentes primarias: declaraciones orales y documentos escritos. Fuentes secundarias: literaturas sobre la temática. Referencial teórico: conceptos de Pierre Bourdieu. Las estrategias de lucha emprendidas por los agentes de la enfermería acontecieran a partir de directrices político-expansionistas, político-jurídicas, y político-organizacionales, las cuales concurrieran para la reconfiguración del campo de la educación superior de enfermería.

Descriptores: Enfermería; Historia de la enfermería; Educación en enfermería.

AUTOR CORRESPONDENTE Maria Lelita Xavier. Escola de Enfermagem Anna Nery. Rua Afonso Cavalcanti, 275 - Cidade Nova. CEP 202 I I-I I0. Rio de Janeiro - RJ. 


\section{INTRODUÇÃO}

Este estudo tem como objeto as estratégias de luta de portavozes da enfermagem frente às diretrizes emanadas da Lei de Diretrizes e Bases da Educação Nacional (LDB no 9.394/1996) para a educação superior de enfermagem. A LDB/96 foi promulgada no governo do presidente Fernando Henrique Cardoso (FHC), em complementação à Constituição Federal Brasileira (CFB), atendendo à orientação neoliberal vigente no país.

$\mathrm{O}$ Estado, visando à implantação da reforma educacional, e tendo como porta-voz o Ministério da Educação (antigo MEC), o Qual concentra diversos tipos de capital investiu em seu capital jurídico (capital simbólico objetivado e codificado) e elaborou um arcabouço legal constituído de leis, decretos, portarias e resoluções. Dentre estes, destacamos o Plano Nacional de Educação-Lei no 10.172/ 2001 (PNE/200I) Que objetivou operacionalizar as mudanças e regulamentar a legislação em termos de traduzir a política educacional em estratégias de cumprimento da lei.

Os instrumentos legais expressavam princípios como expansão, flexibilidade, diversificação, avaliação e modernização(1) e determinavam como diretrizes: estabelecer um conjunto diversificado de instituições Que atendam a diferentes demandas e funções; expansão com Qualidade Que ressaltasse a importância do setor privado; ampliação da margem de liberdade das instituições não-universitárias; permanente avaliação dos currículos; expansão de vagas no período noturno; e institucionalização de um amplo sistema de avaliação ${ }^{(2)}$.

A implantação da nova política educacional acarretou mudanças estruturais no campo da educação superior de enfermagem. Dentre estas, citamos: extinção do currículo mínimo e adoção de diretrizes curriculares; definição de carga horária mínima de duração do curso; grande aumento do número de cursos de enfermagem, principalmente no setor privado; criação de cursos de enfermagem em centros universitários e faculdades isoladas; ampliação do ingresso de estudantes tanto pela adoção de diversas formas de processo seletivo como pelas políticas de acesso, tais como: Exame Nacional do Ensino Médio (ENEM), Programa Universidade para Todos (PROUNI); oferta de cursos no horário noturno; avaliação do aluno e das condições de oferta do curso.

Todo campo é constituído por diferentes agentes os Quais assumem posições distintas de acordo com o volume global de capital de Que dispõem, e estão constantemente em luta para obterem uma melhor posição no mesmo ${ }^{(3)}$. Uma vez que o campo da educação superior de enfermagem também segue esta dinâmica, seus agentes estabeleceram estratégias de luta visando enfrentar o poderio do MEC, no sentido de continuarem a manter suas posições de poder e de prestígio e assim poder enunciar em discurso autorizado frente à nova ordem Que se impôs.

Para tanto, os agentes Que ocupavam diversas posições no campo da educação superior de enfermagem organizaram-se em torno da Associação Brasileira de Enfermagem (ABEn) para discutir Questões pertinentes à formação do enfermeiro. E isto porQue, reconheceram Que o Quantum de capital social desta instituição lhe conferia a distinção de assumir a legítima posição de porta-voz legítimo da categoria.

Assim, traçamos os seguintes objetivos para este estudo: analisar a posição da ABEn no campo da educação superior de enfermagem; discutir estratégias de luta empreendidas por porta-vozes da educação superior de enfermagem frente às diretrizes da LDB/96.

\section{ABORDAGEM TEÓRICO-METODOLÓGICA}

Estudo de cunho histórico-social, com abordagem Qualitativa. As fontes primárias foram constituídas de depoimentos de agentes sociais Que ocupavam os seguintes cargos: Diretoria de Educação da ABEn nacional e responsáveis por cursos superiores de enfermagem - e de documentos escritos - leis, decretos, pareceres, portarias, regimentos, manual de avaliação de cursos, censo da educação superior, relatórios e anais dos Seminários Nacionais de Educação de Enfermagem (SENADEn's), documentos pertencentes aos areuivos da ABEn nacional e regionais e ao Instituto Nacional de Ensino e Pesquisa Anísio Teixeira/MEC.

As fontes secundárias incluíram literatura de história da educação e da enfermagem, principalmente as relacionada ás políticas públicas de educação.

A análise e a discussão dos achados foram orientadas pela ordenação cronológica e temática das fontes primárias, pelas fontes secundárias e pelos conceitos de Pierre Bourdieu, tais como: campo, capital, habitus, poder e violência simbólica.

Vale esclarecer Que os entrevistados autorizaram a utilização de seus depoimentos neste estudo e Que, além disto, doaram os mesmos para o Centro de Documentação da Escola de Enfermagem Anna Nery, da Universidade Federal do Rio de Janeiro. O projeto Que deu origem a este artigo foi aprovado pelo Comitê de Ética em Pesquisa da EEAN/UFRI, em 29 de abril de 2008.

\section{RESULTADOS E DISCUSSÃO}

\section{A ABEn e o campo da educação superior de enfermagem}

A ABEn, fundada em 1926, é uma entidade de classe de cunho associativo, detentora de considerável volume de capital social. Ao longo de sua trajetória seu estatuto passou por várias reformas visando atender às legislações brasileiras e também para enfrentar os desafios Que se apresentavam à profissão. Um deles se refere às Questões educacionais, pois as mesmas sempre estiveram na sua agenda de trabalho e continuam demandando muito empenho e dedicação de seus membros.

Em 1939, foi organizada a primeira Comissão de Educação da ABEn, com o objetivo de auxiliar a diretoria nas atividades de elaboração e acompanhamento dos projetos de criação de novas escolas. Em 1945, esta Comissão passou a ser denominada Divisão de Ensino de Enfermagem, posteriormente Divisão de Educação e em 1955, passou a chamar-se Comissão de Educação( ${ }^{(4)}$. Permaneceu com esta denominação até a década de 1980, Quando se tornou Comissão Permanente de Educação. Em meados da década de 1990, no contexto de uma reforma global do estatuto da ABEn, adeuiriu o status de Diretoria de Educação. Esta Diretoria administra os três níveis de ensino mediante as seguintes Comissões Permanentes: Habilitação de Técnico de Enfermagem, de Graduação e de Pós-Graduação ${ }^{(5)}$.

A Diretoria de Educação tem status e predicados, ou seja, volume global de capital para estar no jogo e impor os objetivos Que mais interessam à educação em enfermagem no campo da educação brasileira. Desde a sua criação vem tendo importante participação 
nas atividades relacionadas às diretrizes para a formação do enfermeiro, por meio de amplo e permanente debate, em eventos regionais e nacionais, acerca do ensino de enfermagem e da definição de políticas de formação. No Que se refere ao objeto desta pesQuisa, em 1991, a ABEn apresentou à Secretaria de Ensino Superior (SESU/MEC) o documento: Proposta de Novo Currículo Mínimo para o Ensino Superior de Enfermagem. No âmbito do MEC, este documento sofreu alterações e deu origem à Portaria/MEC $n^{\circ}$ 1.721 , de 15 de dezembro de 1994, homologada pelo Parecer $n^{\circ}$ 31 4/94 do Conselho Federal de Educação (CFE).

As modificações feitas pelo CFE no documento encaminhado pela $A B E n$ não corresponderam ao esperado pela categoria, o que motivou a continuidade da mobilização nacional e impulsionou a estruturação dos Fóruns Estaduais de Escolas de Enfermagem vinculados às $A B E n s$ regionais, assim como a criação de um espaço exclusivo para as discussões das Questões educacionais, a partir de 1994: os SENADEn's ${ }^{(6)}$. Estes seminários consistem numa articulação da ABEn com as escolas de enfermagem, o Que dá suporte à sua representação junto aos órgãos oficiais de educação e de saúde, já com um novo arranjo institucional para ampliar a sua capacidade de gestão Assim, a ABEn fortaleceu o seu papel de porta-vOz autorizada da enfermagem ${ }^{(3,7)}$.

Ressalta-se que dos SENADEn's de 2002, 2003, 2004 e 2005 a ABEn teve como produto as seguintes Cartas: de Teresina, de Brasília, de Vitória e de Natal. Esses documentos expressam a preocupação dos participantes com as mudanças Que estavam ocorrendo no campo da educação superior de enfermagem, advindas dos desdobramentos da LDB/96.

A dinâmica do campo da educação em enfermagem constituíase em um movimento processual, em espaço de aglutinação dos agentes em torno da ABEn para lutar pelo poder de organizar o ensino da enfermagem, de modo a reatualizar o habitus de classe.

\section{Estratégias de luta de porta-vozes da enfermagem frente à LDB/96}

As estratégias de luta colocadas em prática pelos agentes da enfermagem e pela sua porta-voz - a ABEn, aconteceram a partir de diretrizes político-expansionistas, político-jurídicas, e políticoorganizacionais, as Quais estavam articuladas aos princípios Que nortearam a reforma educacional, e Que concorreram para a reconfiguração do campo da educação superior de enfermagem. Tais estratégias visavam assegurar as condições necessárias para a atualização do habitus profissional, afiançar maior capital cultural aos agentes envolvidos no processo e minimizar o impacto das legislações no campo.

As estratégias relacionadas às diretrizes político-expansionistas abrangeram aspectos como o modo de acesso e a proposta de cursos seuüenciais e de tecnólogos. Entre as mudanças ocasionadas pela LDB/96 a expansão é o elemento principal da condução das políticas de educação no país. Os agentes da enfermagem atentam para esta Questão no $2^{\circ}$ SENADEn e propõem Que na esfera federal a Comissão de Especialistas de Enfermagem acompanhe os processos de criação de cursos de enfermagem; e Que na esfera estadual, seja realizado o controle social pela categoria Quanto à criação de novos cursos através das ABEns regionais e dos Fóruns de Escolas ${ }^{(8)}$

No $3^{\circ}$ SENADEn (1998) foi reconhecida a importância da expansão do número de cursos de enfermagem na rede pública de ensino superior. Porém, o Que se verifica é Que o número de cursos aumentou na rede privada. Tanto Que, em 1996, ano da promulgação da LDB existiam I I I cursos sendo 66 públicos e 45 privados no ano de 2001 constatou-se a existência de 215 cursos, sendo 75 públicos e 140 privados.

Assim é Que frente a este contexto de expansão de cursos superiores de enfermagem a estratégia adotada pelos agentes da enfermagem foi fazer aliança com a Comissão de Especialistas de Ensino de Enfermagem (CEEEnf) instituída pela Portaria SESu/ MEC no 1.51 8/2000 para realizar uma Oficina de Trabalho com as diretorias de educação das $A B E n s$ regionais. Esta oficina foi realizada em 2001, logo após o $5^{\circ}$ SENADEn $^{(9)}$ e teve como finalidade discutir critérios de autorização e avaliação dos cursos de enfermagem.

A preocupação dos enfermeiros com a abertura indiscriminada de cursos superiores de enfermagem continuou em 2002, na Carta de Teresina, elaborada no $6^{\circ}$ SENADEn, Que tratou da Qualidade dos cursos de enfermagem presenciais.

$\mathrm{O}$ aumento do número de cursos superiores de enfermagem também era alvo de preocupação dos agentes sociais responsáveis por cursos de graduação. Quanto à Qualidade e à determinação de critérios para sua abertura, assim expressou sua opinião uma das depoentes:

Eu acho que estão abrindo cursos com muita facilidade, com professores horistas, sem carreira em magistério. Eu vejo este aumento com muita preocupação (D3).

Com o número de cursos vinculados ao setor privado se multiplicando, outra matéria a ser examinada era o modo de acesso aos mesmos. $\mathrm{O}$ ingresso no curso superior de enfermagem vinha de uma realidade, anterior à LDB/96, de vestibulares rigorosos, como ainda hoje pode ser observado nas instituições de ensino superior público.

No caso da enfermagem, o processo seletivo diversificado favoreceu a entrada de grande número de alunos, principalmente de candidatos com formação de auxiliar e/ou técnico de enfermagem, os Quais viram neste contexto de flexibilização a oportunidade de ascensão social através da profissão, pela busca do capital institucionalizado que o irá legitimar a exercer o cargo de enfermeiro.

A entrada destes agentes no jogo demandou estratégias para corrigir as deficiências na formação escolar anterior, pois Que não possuíam capital cultural apropriado para acompanhar o jogo. Então, o Que resta é sair do jogo, daí a evasão escolar; ou permanecer no jogo, mas tendo que se submeter às suas regras. De acordo com a experiência de uma das autoras deste trabalho, como coordenadora de curso de enfermagem, a estratégia foi a criação do programa de nivelamento \% Que consistia na inclusão de matérias como: Leitura, interpretação e produção de texto, Raciocínio Lógico e Formação para a cidadania como parte da matriz curricular além do oferecimento de cursos de extensão de língua portuguesa e matemática.

A escola, em Bourdieu, realiza uma "operação de triagem" na medida em que mantém a ordem pré-existente, separando alunos em diferentes graus de capital cultural. A classificação escolar é um ato de ordenação, no sentido de diferença social, em Que os 
eleitos são marcados como pertencentes a esta ordem e os demais são excluídos do sistema ${ }^{(10)}$.

Quanto aos cursos seqüenciais observa-se, nos documentos analisados, um movimento de Questionamento por parte de instituições de ensino e de órgãos de classe das categorias profissionais Quanto à sua implantação, uma vez Que o entendimento sobre esta Questão não ficou claro, carecendo de definição dos seus propósitos e características, por parte do MEC.

A estratégia dos agentes da enfermagem neste caso foi participar dos vários espaços onde se discutia cursos seeüenciais assim como fazer alianças com outras instituições de ensino, representantes de diferentes categorias profissionais, como a Universidade Federal do Estado do Rio de Janeiro (UNIRIO) e a participação no Encontro Nacional do Fórum de Pró-Reitores de Graduação em 1999. Nesses encontros a discussão acerca desse assunto era acalorada e expressiva do posicionamento contrário dos agentes da saúde. Segundo uma depoente:

Discutimos muito [...] inclusive eu sei Qual era a posição do Fórum de Escolas do Rio de Janeiro [contrária] em relação aos cursos seqüenciais, que era uma extensão para o tecnólogo. Lembro Que, na época, a pró-reitora de graduação [da UNIRIO], ex-diretora da Escola de Enfermagem Alfredo Pinto e posteriormente do INEP fez grande discussão e explicou o significado do curso seqüencial. Acredito que não só a área de saúde vetou, mas outras também (D4).

Entre os profissionais da enfermagem, os cursos seQüenciais causaram polêmica, tendo em vista Que a profissão já comportava diferentes tipos de exercentes como: auxiliar de enfermagem, técnico de enfermagem e enfermeiro. Uma agente entrevistada assim se expressou:

Os cursos seQüenciais e tecnólogos não dariam um profissional de nível superior. Eu não vejo o curso seQüencial e tecnólogo como melhoria para a saúde da comunidade. Seria uma pessoa a mais para dividir, não para somar... (D5).

Depreende-se dos depoimentos Que os porta-vozes autorizados dos cursos de enfermagem não aprovaram a criação de mais uma categoria na enfermagem. Cada agente estava preocupado em preservar a posição do enfermeiro como o único detentor de nível superior no campo da educação de enfermagem, pois consideraram Que a inserção de outras categorias poderia contribuir para a redução do status profissional.

No $4^{\circ}$ SENADEn, realizado em 2000, foi debatido o tema Cursos Seqüenciais: implicações para a prática de enfermagem, apresentado pelas professoras lara de Moraes Xavier (à época Coordenadora da CEEEnf) e Maria Henriqueta Luce Kruse (à época Vice-Presidente da Câmara de Graduação e Membro do Conselho de Ensino, Pesquisa e Extensão da Universidade Federal do Rio Grande do Sul). Esta última ressaltou Que, diante de assunto tão polêmico, a enfermagem brasileira deveria assumir uma atitude responsável e desaconselhar a criação destes cursos, pois implicaria a criação de mais uma categoria profissional na enfermagem ${ }^{(9)}$.

A Questão dos cursos tecnólogos surgiu mais uma vez em 2002, Quando o Conselho Nacional de Educação (CNE) propôs a discussão, em audiências públicas, de uma proposta de Resolução sobre Diretrizes Curriculares Nacionais para a Educação Profissional de Nível Tecnológico, com o objetivo de criar tais cursos inclusive para área da saúde e, conseQüentemente, para a enfermagem.

A ABEn participou ativamente das audiências públicas organizadas pelo CNE, e parece ter influenciado para firmar o posicionamento contrário da categoria Quanto à criação de cursos seQüenciais e tecnológicos na área da enfermagem. Tanto que, até o momento, os mesmos não foram implantados no campo da educação superior de enfermagem.

As diretrizes político-jurídicas envolveram aspectos legais relacionados principalmente aos documentos oficiais Que normatizavam e regulavam o processo avaliativo e a supervisão do sistema federal de ensino.

Para enfretamento das Questões advindas da LDB/96 uma das principais estratégias de luta empreendida pela $A B E n$ foi a tomada de decisão visando a realização anual do SENADEn. Para isso seus agentes envidaram um Quantum de força, pois entendiam Que as mudanças deviam ser discutidas, em âmbito nacional, e pelo maior número de agentes envolvidos na situação.

Outra estratégia da ABEn foi estabelecer parcerias com instituições formadoras e com instâncias do MEC responsáveis pela regulamentação e avaliação da formação de profissionais da área da saúde. Neste sentido, a ABEn levou o assunto da avaliação para o $5^{\circ}$ SENADEn, realizado em 2001 , em São Paulo, Que teve como tema central A Avaliação no Contexto das Diretrizes Curriculares para a Educação em Enfermagem: prioridades, implicações e desafios. A discussão levou em consideração os diferentes aspectos Que compõem a avaliação educacional, a saber: avaliação institucional relacionada ao corpo docente e ao projeto pedagógico, incluindo-se a autoavaliação como estratégia de seu reconhecimento $^{(1 \mathrm{I})}$.

A Questão do Exame Nacional de Curso (ENC) também conhecido como provão, foi discutida em diversos espaços sociais e com diferentes agentes, tendo como principal opositor a União Nacional de Estudantes (UNE) e o Fórum Nacional em defesa da Escola Pública:

No SENADEn de 2002, no Piauí, houve discussão dos alunos, da Executiva Nacional para boicote ao Provão; principalmente os alunos pernambucanos e baianos. Mas no Rio de Janeiro, nós não tivemos boicote. Para nós, o [provão], desde o primeiro momento, foi muito importante... (D7).

Na prática, o que se percebeu foi Que o ENC funcionou como um instrumento isolado de avaliação, voltado apenas para um de seus aspectos: o desempenho dos estudantes - sendo amplamente divulgados os seus resultados na midia, como um ranking de classificação das melhores e piores instituições, objetivando estimular a concorrência, já Que as instituições utilizavam os resultados para se promoverem. O Exame Nacional de Desempenho dos Estudantes (ENADE) substituiu o ENC, mas ainda assim houve resistência por parte dos alunos, Que insistiam em não Querer participar do processo. Pela obrigatoriedade do exame, os dirigentes dos cursos superiores tinham que persuadi-los:

Eu chamei os alunos e disse para eles: - vocês têm o direito de 
fazer o Que Quiserem, mas se a instituição tirar nota baixa, um ano depois se recupera; agora, no diploma de vocês vai ter um conceito o resto das suas vidas. Todos fizeram a prova (D2).

A Carta de Natal, elaborada em 2005, por ocasião do $9^{\circ}$ SENADEn, apresentou diversas propostas, entre elas o "estabelecimento de estratégias para a regulação da Qualidade do ensino e para abertura de novos cursos de graduação, bacharelado..." ${ }^{(12)}$. O depoimento a seguir evidencia a inadeQuação dos critérios existentes para a abertura de cursos de enfermagem em Instituição de Ensino Superior (IES) principalmente em universidades e centros universitários independente de sua categoria administrativa

O reitor da instituição autorizava a criação de cursos e o MEC só comparecia para o momento do reconhecimento. [...] de uma forma extremamente ousada organizaram o processo de vestibular, teve procura de aproximadamente Quarenta e cinco alunos para a primeira turma. Só depois que começaram a contatar pretensos coordenadores para o curso. Eu até identifieuei isso como sendo uma conduta irresponsável. A instituição não tinha nem o projeto do curso (D6).

Revelando a posição da enfermagem sobre o processo de avaliação da educação superior, para além de instrumentos legais e regulatórios, o $9^{\circ}$ SENADEn teve como tema $A$ Qualidade da Educação: um compromisso social da enfermagem, cujo objetivo foi refletir sobre a Qualidade da educação brasileira, focando criticamente a articulação do ensino, do trabalho e da pesQuisa, como um dos fatores determinantes de Qualificação na formação profissional na perspectiva do seu compromisso social ${ }^{(12)}$.

As estratégias de luta relativas às diretrizes políticoorganizacionais demonstraram a preocupação dos agentes sociais organizados em torno da ABEn com os projetos pedagógicos dos cursos no Que diz respeito principalmente aos cursos noturnos, às diretrizes curriculares e à carga horária para conclusão do curso.

Quanto ao funcionamento dos cursos superiores de enfermagem no período da noite a maioria dos agentes da enfermagem entendia Que esta situação ainda carecia de muitos debates e nem mesmo existiam documentos legais Que normatizassem seu funcionamento. Porém, a existência de cursos noturnos era uma realidade Que não poderia ser desconsiderada. Tanto assim Que, no $8^{\circ}$ SENADEn, em 2004, na Carta de Vitória, este assunto veio à pauta e nela está expresso Que o ensino noturno deveria ser compreendido como um espaço Que refletisse a especificidade do trabalho em enfermagem; deveria estar articulado com as legislações trabalhistas e Que deveriam existir diretrizes específicas para os cursos noturnos ${ }^{(13)}$. Um agente desta pesquisa assim se pronunciou acerca do oferecimento de cursos noturnos:

A coordenação do curso até o semestre passado foi contrária à criação do curso noturno, mas infelizmente fugiu das nossas mãos e foi aberto sem consulta porque era um desejo da universidade. Fomos chamadas depois para atender as diretrizes em relação à carga horária Que deve ser majoritariamente diurna (DI).

Outra Questão relaciona-se às Diretrizes Curriculares (DCs). O
MEC, através do Edital no 4, de 1997, convidou agentes de diferentes profissões para elaborarem as diretrizes curriculares referentes às suas áreas de conhecimento. Em atenção a este chamamento, a ABEn, estrategicamente promoveu o $3^{\circ}$ SENADEn, em 1998, Que teve como tema central Diretrizes para a educação em enfermagem no contexto da LDB/96 (14). As discussões continuaram no ano seguinte, durante o $51^{\circ}$ Congresso Brasileiro de Enfermagem realizado em Florianópolis, Que foi o espaço social de construção coletiva e de deliberação do documento final das diretrizes curriculares para os cursos de enfermagem ${ }^{(1-6)}$.

Vale lembrar que o documento intitulado Enquadramento das Diretrizes Curriculares, gerou repercussão negativa no campo da educação superior de enfermagem. Seu conteúdo resgatava as antigas habilitações e criava cursos seQüenciais, Questões estas discordantes do Que o grupo organizado em torno da ABEn apresentou. Desse modo, os agentes empreenderam estratégias de luta visando reverter a situação. Os membros da CEEEnf, nomeada em 2000, em aliança com os porta-vozes do campo da educação em enfermagem, elaboraram um outro documento Que deu origem à Resolução do Conselho Nacional de Educação/Câmara da Educação Superior (CNE/CES), no 3, de 7 de novembro de 2001 a Qual instituiu as DCs para os cursos de Graduação em Enfermagem.

Aprovadas as DCs, a etapa seguinte foi elaborar estratégias para a sua implantação pelos cursos superiores de enfermagem. As mudanças foram discutidas no $6^{\circ}, 7^{\circ}$ e $8^{\circ}$ SENADEn's realizados em 2002, 2003 e 2004, respectivamente. A Carta de Brasília (2003) relata o trabalho das oficinas Que abordaram a análise crítica das experiências de implantação das DCs nos cursos superiores de enfermagem ${ }^{(11)}$.

Uma depoente relata a sua estratégia de implantação das DCs:

Foi exercício de explicar, fazer muitas oficinas para resguardar Que ninguém se sentisse alijado do processo. Eu nunca vou me esquecer, o projeto pedagógico da Escola foi aprovado em colegiado de curso, com presença maciça (D4).

Em relação à carga horária do curso de enfermagem, os participantes do $3^{\circ}$ e do $4^{\circ}$ SENADEn's propuseram que o curso superior de enfermagem fosse ministrado em no mínimo 3.500 horas $^{(6)}$, mas entendiam Que era necessário definir um parâmetro de referência nacional. Assim, através da Carta de Teresina, elaborada no $6^{\circ}$ SENADEn (2002) tomaram a iniciativa de propor para o curso de enfermagem a duração mínima de 4.000 horas, com um tempo de integralização de, no mínimo, oito semestres ou Quatro anos letivos.

A Questão da carga horária dos cursos foi retomada por meio do Parecer CES/CNE no 108/2003, de 7 de maio de 2003, Que tratava da duração de cursos presenciais de bacharelado, indicando Que o CNE promoverá nos próximos seis meses, audiências com a sociedade, ensejando a discussão e avaliação da duração e integralização dos cursos de bacharelado e Que ao final desse processo, aprovará Parecer e Resolução dispondo sobre a matéria. Este Parecer definiu a duração mínima dos cursos de graduação em três anos com integralização mínima de 2.400 horas, exceto para os cursos de medicina, direito e engenharia. Isto resultou em manifestações contrárias por parte de diversos órgãos de classe do 
campo da saúde. Tanto Que a ABEn Nacional encaminhou para o Presidente da CNE, professor Efrém de Aguiar Maranhão, o documento Considerações da ABEn à Minuta do Parecer no 108/ 2003 Que consistia na argumentação da definição da carga horária de 4.000 horas para integralização do curso superior de enfermagem como subsídio às discussões da Audiência Pública promovida pela CES do CNS, a ser realizada em 16 de dezembro de 2003, em Brasília. Através deste, a ABEn fez considerações contundentes sobre o referido Parecer e seu teor demonstrou enfaticamente a posição da enfermagem em relação a tal assunto, ali representada pela sua entidade de classe.

As considerações apresentadas reúnem um conjunto de reflexões realizadas pelos profissionais de enfermagem aos Quais a ABEn representa, ao delegá-la a interlocução com o CNS/CES, partícipes dos Fóruns de Escolas de Enfermagem, Seminários de Diretrizes para a Educação em Enfermagem, Plenárias de Escolas e Diretores de Educação das Seções e Regionais existentes nos estados da federação. [...] neste momento do seu desenvolvimento histórico, a formação superior em Enfermagem deverá ter como carga horária mínima 4.000 horas, integralizadas em Quatro anos, para Que possa vivenciar as mudanças na formação destes profissionais, possibilitadas pelas DCNs, e avaliá-las de forma sistemática e consistente, visando definir "o tempo útil" Que expressará o aproveitamento e o compromisso social desta formação ${ }^{(16)}$.

Em 2004, foi aprovado o Parecer no 329/2004, relacionado ainda à definição da carga horária mínima para todos os cursos de graduação. Em 2006, foi aprovado o Parecer no 184 do CNE/ CES, Que tratou da retificação do Parecer CNE no 329/2004, referente à carga horária dos cursos, nele foi definido carga horária para vários cursos, porém a enfermagem não estava incluída ${ }^{(16)}$.

O fato é Que a enfermagem, representada pela sua porta-voz, a ABEn Nacional, não se sentiu contemplada em seu pleito de fazer valer a posição defendida e discutida ao longo do tempo. Esta, por sua vez, solicitou Que as ABEns regionais se manifestassem sobre o Parecer no 329/2004, no Que foi atendida. A Presidente da ABEn, Francisca Valda da Silva, enviou o ofício/ABEn no 36/2005 ao então Presidente do CNE, Roberto Cláudio Frota Bezerra, e anexou a ele o documento Considerações da ABEn à Minuta do Parecer no 108/2003.

Exemplificando a luta dos agentes da enfermagem pela definição da carga horária apresentamos a fala Que se segue:

O grupo discutia exaustivamente a carga horária porQue o MEC Queria reduzir, e qualquer hora nós seríamos técnicos (D2).

A não-aceitação por parte do CNE da carga horária proposta pelo grupo de agentes da enfermagem teve repercussão de tal monta Que a luta pela sua definição se estendeu del997 até o ano de
2008, Quando foi aprovado o Parecer CNE/CES no $213 / 2008$, homologado em 1 1/03/2009, pelo Ministro da Educação Fernando Haddad, definindo Que a carga horária mínima dos cursos superiores de enfermagem seria de 4.000 horas.

Assim é Que, a luta conjunta dos responsáveis por cursos superiores de enfermagem, dos membros da CEEEnf do MEC e dos membros das diretorias da ABEn foram eficazes para fazer valer as $4.000 \mathrm{~h}$ consideradas como adeQuadas para a formação do habitus profissional do enfermeiro.

\section{CONSIDERAÇÕES FINAIS}

As estratégias de luta estabelecidas e empreendidas por agentes da enfermagem, em consonância com a ABEn, se deram a partir de diretrizes político-expansionistas, político-jurídicas, e políticoorganizacionais, Que estavam articuladas aos princípios de expansão, flexibilidade, diversificação, avaliação e modernização, os Quais ao nortearem a reforma educacional brasileira, concorreram para a reconfiguração do campo da educação superior de enfermagem. Para esses agentes foi necessário dar a conhecer e fazer reconhecer Que as repercussões advindas da implantação das diretrizes da LDB/96 eram problemas legítimos, publicáveis, públicos, oficiais, e produzidos pelas circunstâncias sócio-políticas e econômicas. Assim, através de reuniões, comissões, manifestações, eventos, petições, requerimentos, tomadas de posição, os enfermeiros os tornaram problemas sociais, demandando um trabalho coletivo de construção para uma nova realidade Que se aplicasse à reconfiguração dos cursos superiores de enfermagem.

Objetivando a discussão coletiva sobre as Questões do campo da educação em enfermagem, os SENADEn's se firmaram como espaços de discussão e elaboração de estratégias de luta para subverter a nova ordem estabelecida pela LDB/96 e seus desdobramentos, para o campo da educação superior, colocados como a única verdade pelos agentes do MEC.

Destacamos que a ABEn, desde os seus primórdios, se constituiu em locus de definição das posições e disposições no campo da educação superior de enfermagem, visando a enunciação de um discurso autorizado sobre a formação do enfermeiro ${ }^{(17)}$.

Concluímos que a ABEn se destacou como porta-voz atuante e competente na condução das Questões inerentes ao campo da educação superior de enfermagem, e também Que a força da sua autoridade científica proveniente do grande volume dos diversos tipos de capital acumulados ao longo de sua trajetória, possibilitou Que os enfermeiros obtivessem êxito nas principais Questões decorrentes da LDB/96. Por isso mesmo, seus porta-vozes possuem a capacidade de falar e de agir legitimamente, isto é, de maneira autorizada e com autoridade, a Qual é socialmente outorgada a agentes determinados.

\section{REFERÊNCIAS}

1. Rodrigues RM. Diretrizes curriculares para a graduação em enfermagem no Brasil: contexto, conteúdo e possibilidades para a formação [tese]. Campinas: UNICAMP; 2005.

2. Brasil. Lei $n^{\circ} 10.172$ de 09 de janeiro de 2001. Aprova o Plano Nacional de Educação e dá outras providências. Diário Oficial da União; 2001.

3. Bourdieu P. Os escritos da educação. Petrópolis: Vozes; 1998.

4. Carvalho AC. Associação Brasileira de Enfermagem 19261976. Brasília: ABEn Nacional; 2006.

5. Associação Brasileira de Enfermagem. Estatuto. Brasília; 2005. [citado em 23 abr 2009]. Disponível em: http:// www.abennacional.org.br/download/Estatuto_ABEn_.pdf. 
6. Moura A, Liberalino FN, Silva FV, Germano RM, Timóteo RPS. SENADEn: expressão política na educação em enfermagem. Rev Bras Enferm 2006; 59(esp): 442-53.

7. Vale EG; Fernandes ID. Ensino de graduação em enfermagem: a contribuição da Associação Brasileira de Enfermagem. Rev Bras Enferm 2006; 59 (esp): 417-22.

8. Associação Brasileira de Enfermagem. Anais do Seminário Nacional de Diretrizes para a Educação em Enfermagem; Florianópolis (SC), Brasil. Florianópolis: ABEn; 1997.

9. Mancia IR. Padilha MICS, Reibenitz KS. A Contribuição dos Senadens para a construção das diretrizes Curriculares da Enfermagem. Anais do Seminário Nacional de Diretrizes para Educação em Enfermagem no Brasil. Teresina (PI), Brasil.Teresina: ABEn; 2002.

10. Maciel CM. O lugar da escola técnica frente às aspirações do mercado de trabalho [dissertação]. Rio de Janeiro: Instituto de Filosofia e Ciências Sociais, Universidade Federal do Rio de Janeiro; 2005.

11. Associação Brasileira de Enfermagem. Educação em enfermagem buscando a coerência entre intenções e gestos. Anais do Seminário Nacional de Diretrizes para a Educação em Enfermagem. Brasília (DF), Brasil. Brasília: ABEn; 2003.

12. Associação Brasileira de Enfermagem. Qualidade da educação como compromisso social da enfermagem. Anais do Seminário Nacional de Diretrizes para a Educação em Enfermagem. Natal (RN), Brasil. Natal: ABEn; 2005.

13. Associação Brasileira de Enfermagem. Educação em enfermagem: Discutindo mudanças, pesquisando o novo e superando desafio. Anais do Seminário Nacional de Diretrizes para a Educação em Enfermagem. Vitória (ES), Brasil. Vitória: ABEn; 2004.

14. Associação Brasileira de Enfermagem. As diretrizes para a educação em enfermagem no contexto da LDB: Relatório. Anais do Seminário Nacional de Diretrizes para a Educação em Enfermagem. Rio de Janeiro (RJ), Brasil. Rio de Janeiro: ABEn; 1998.

15. Associação Brasileira de Enfermagem. Considerações da ABEn à minuta do Parecer CES/CNE No 108/2003. Brasília: ABEn Nacional; 2003.

16. Ministério da Educação (BR). Conselho Nacional de Educação. Parecer No 184 de 07 de julho de 2006. Retificação do Parecer CNE no 329/2004, referente à carga horária mínima dos cursos de graduação, bacharelados, na modalidade presencial. Brasília: MInistério da Educação; 2006

17. Baptista SB, Barreira IA. Enfermagem de nível superior no Brasil e vida associativa. Rev Bras Enferm.2006; 59(esp): 4I I-6. 